\title{
Strengthening Visual Media Literacy in the Discovery of Style and Creativity in Packaging Design for Chips
}

\author{
Wegig Murwonugroho \\ \{wegig_besar@yahoo.com\} \\ Faculty of Fine Arts and Design -Universitas Trisakti Jl. Kyai Tapa No.1, RT.6/RW.16, Tomang, \\ Grogol petamburan, Kota Jakarta Barat, Daerah Khusus Ibukota Jakarta 11440
}

\begin{abstract}
Chips are traditional Indonesian food. These snacks are made from cassava, tempeh or fruits. Some small industrial centers make chips a staple of livelihood. Small industries must compete with modern industries. However, due to the existence of traditional markets, mini markets, and grocery stalls, the chips industry continues to survive. Packaging design has a role to attract buyers. The combination of illustrations, photos, typography, color, and shape of the packaging sometimes fails to attract the desire of buyers to try certain chips. This study aims to find out which packaging has high attractiveness. The research method used is a qualitative analysis method based on social construction theory consisting of stages: 1). objectification; 2). internalization; and 3). externalization. The results of the study show that packaging that is more desirable to consumers is: 1). The concept of eastern cultural philosophy, objectified with graphic ornament area icons. 2). Consumer interpretation is built when repeated packaging illustrations are set or seen when consumers consume these foods; 3 ). There are social context narratives that are discourse and deliberately disseminated through social media. These three findings are the basis for packaging design that is creative and has selling value. Strengthening the deepening of visual media literacy in the internet world makes the solution at every stage of the packaging design process to truly understand the packaging trend.
\end{abstract}

Keywords: Packaging Design; Externalization; Internalization; Objectification.

\section{Introduction}

The pleasure of eating chips or snacking is one of the widely common traditions in Indonesia. Chips are one of the favorite snacks among many others. Chips that are made from cassava are the most popular variety with the highest demand on the market. In addition to cassava, there are other varieties of chips that are made of tempeh, and dried fruits. These main ingredients are thinly sliced and fried until a certain level of crispiness. Various flavorings are sprinkled to add taste and make consumers continuously enjoy chips.

The production of chips technically considered simple. This can be done by housewives and small industries. With trial and error, various chips for production are spent with the hope that the chips will sell well. Various training in the chips industry have also been followed, but the results are still not optimal. The problems, in this case, are: the orientation carried out so far is how the production process. Not on how to pack the products to look more attractive and have more selling value. Not only that, but the aesthetic power must also be followed by a strong philosophical concept. Finally, the packaging of crispy snacks cannot compete with the 
packaging of chips that already exist, especially with large-scale and modern industrial chips. The results of observations in the field show that most (more than $70 \%$ ) visitors choose the food packaging chips that have been known.
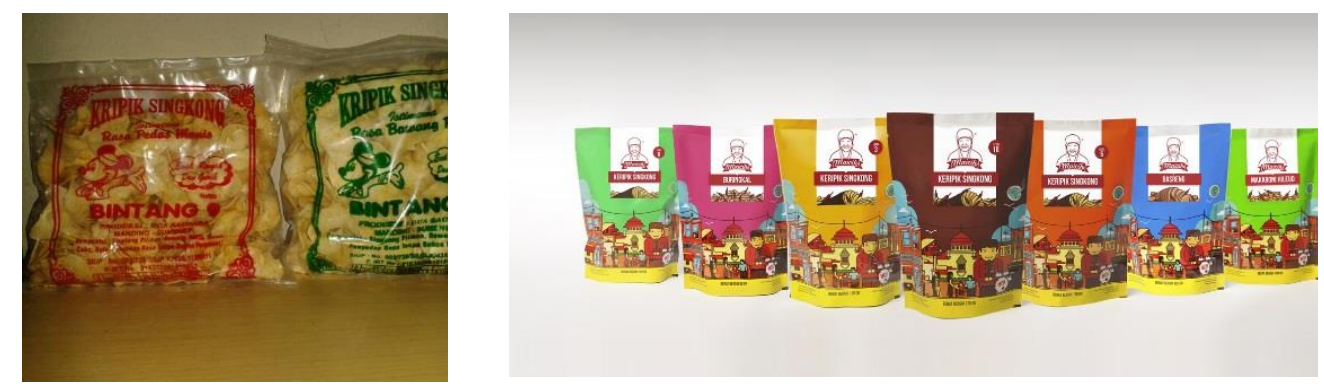

Fig 1. Comparison between Traditional Chips Packaging to the much modern Chips Packaging style (Source: https://bit.ly/2EKQay4, https://bit.ly/2TdUAS8)

Keripik Maicih is a phenomenal brand of chips. These chips are served with various degrees of spiciness. The quality of the new Maicih packaging design looks classy and create more value than just a regular chips product. Unlike the traditional packaging that uses basic colors and the selection of unlicensed Mickey Mouse character. Apart from the taste quality and spiciness level, does the illustration on the packaging have a certain influence on the product image? This background is the basis of the importance of understanding how to design good, creative packaging and the main thing is to improve the product's positive image. This research is one form of solution to improve packaging literacy design.

\section{Methodology}

The research method used is a qualitative analysis method based on social construction theory consisting of these three stages: 1). objectification; 2). internalization; and 3). externalization. The time and place of research are conducted in Jakarta, Bogor, Tangerang, and Bekasi. The target of this research is the small-scale chips industry entrepreneur and also the chips packaging designer. The subject of this research is specifically on chips. The data studied are a). the packaging of chips on minimarkets and stalls display; b). visitor response to packaging design; and 3). social media interaction when eating chips.

\section{Results}

Packaging design is a part of a creative business that combines shape, structure, material, color, image, and typography and other design elements with product information so that products can be well marketed. Packaging design is activated to encapsulate, protect, send, publish, store, identify, and differentiate products on the market. Thus, packaging design can be used as a tool to communicate product personality or function uniquely. In addition, visual foreshadow require products to have certain physical and psychological benefits to attract 
consumers' attention. According to Adam and Ali (2014), the visual elements of this packaging can be classified into sizes, graphics, colors, and designs [1].

Packaging design considers many factors to deal with complex marketing problems through comprehensive design methods. Packaging design must be able to function as aesthetics, meaning to communicate with people from different backgrounds, interests and different jobs so that anthropology, sociology, psychology, ethnography research can provide benefits in the process of design and selection of the right design. Packaging is considered as a powerful vehicle of communication between manufacturers or service providers with the consumers. Factors of packaging are categorized into 2 types: visual and informational elements. The visual elements include Colors, Pictures, Fonts, Shapes and Sizes of packaging, and relate more to the affective side of decision making. Informational elements relate to information provided and materials used in the packaging process and are more likely to address the cognitive side of decisions[2]. The study of social and cultural diversity, human behavior, psychological and cultural tastes, and cultural differences can help to understand how visual elements can communicate well the promotion of a product. Understanding psychology and behavioral studies in the same process can help analyze perceptions and motivate people through visual perception. Basic knowledge of language consisting of the use of phonetic, semantic and syntactic help and the exact words of the application. Furthermore, other studies such as architecture, mathematics, material science, business, and international trade are directly related to the field of packaging design. With so many product choices in the minimarket display rack, competition arises between products. Competition finally encourages companies to carry out market differentiation and encouragement to be different from the market. Packaging design serves to communicate product differences visually. Marketers are finally faced with the need to be able to determine the characteristics that distinguish their products and create contrasting products.

At present, packaging attributes, such as size, shape, text, color, material, and graphics, are often used as important marketing tools to achieve marketing goals to ensure customer satisfaction. In addition, this plays an important part in the branding process to communicate the image and identity of the company so that it distinguishes the company from its competitors. Also, the packaging is an effective sales promotion tool that stimulates impulse buying behavior. Based on its cognitive processing, packaging has two attributes: (1) verbal cues; and (2) visual cues [3]). In the verbal cues, a cognitive process needs a certain intentional effort, whereas in visual cues the cognitive process is conducted unconsciously and unintentionally [3]. A process of meaning carried out by each individual towards the environment and aspects outside of him which consist of externalization, internalization and objectification processes. Externalization is an adjustment to the sociocultural world as a human product, objectification is social interaction in an intersubjective world institutionalized or experienced an institutionalization process, and internalization is an individual identifying himself in the midst of social institutions where the individual is a member. [4]

The term social construction of reality (social construction of reality) is defined as a social process through actions and interactions where individuals create continuously a reality that is owned and experienced together subjectively. (Poloma, 2004:301). [4] Piaget, a figure in constructivism, states that the process of constructing knowledge takes place through the process of assimilation and accommodation. Assimilation is a cognitive process by which one integrates new perceptions, concepts, or experiences into the structure or scheme that is already in his mind. Assimilation can be seen as a cognitive process that places and classifies new events or stimuli in existing structures. This assimilation does not cause changes/changes in existing structures/schemes, but rather develops them. This assimilation process continues. 
Each individual always continuously develops this process. [5]. Furthermore, this study was analyzed in 3 (three) stages: 1). objectification; 2). internalization; and 3). externalization.

\section{Discussion}

\subsection{Objectification}

This study shows that the icon of local culture still dominates in the objectification of the concept of eastern culture. This means that visual power by utilizing local cultural icons is still believed to have a strong attraction. The community is tired with illustrations of packaging using photos. Returning to the form of illustrations and imitation of traditional materials indicates that this is traditional food. Objectification is making and creating something that is not an object as an object, which can be used, manipulated, controlled, and known through its physical properties. The concept of packaging design is objectified by adopting current market tastes. For example, the use of the current colors on the packaging.
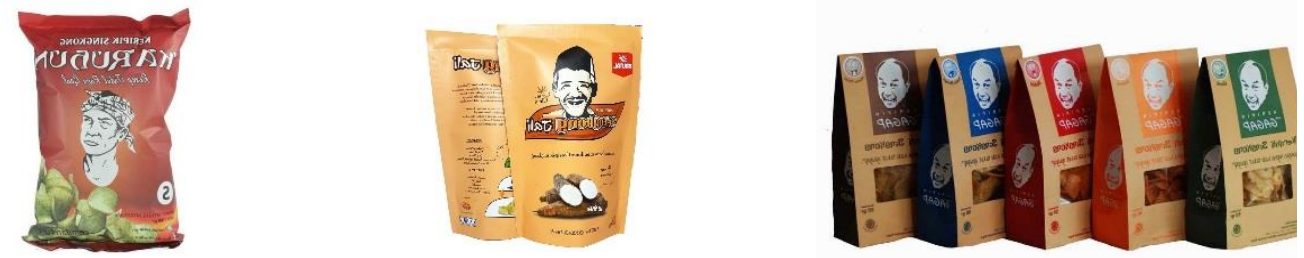

Fig 2. Local Culture Icons in the Objectification of the Sundanese Concept. (Source: https://bit.ly/2EOEXwf, https://bit.ly/2GEOYi9, https://bit.ly/2Q6V6iY )

\subsection{Internalization}

The investigation conducted on the form of packaging by (Arun Kumar Agariya, 2012) shows that consumers' feelings about packaging are actually transferred to how consumers feel about products and innovative packaging forms cutting through the chaos in retail stores and packaging of this kind can create an iconic brand image through its different.[6]. In a qualitative study conducted by (Pinya Silayoi M. S., 2004) on packaging, illustrating that most consumers believe that the form of packaging relates to ease of use and carrying products. [7]

Packaging as a tool for communication was investigated by Butkeviciene et al. (2008), Gonzalez, Thorhsbury \& Twede (2007), Vila \& Ampuero (2007), Nancarrow, Wright \& Brace (1998), Prendergast \& Pitt (1996), Smith \& Taylor (2004), Underwood et al. (2001), Silayoi \& Speece (2004), Underwood (2003), (Vazquez, Bruce \& Studd, 2003; Ampuero \& Vila, 2006), etc." [8]. The tendency of many people to just try new things. They are interested in various searches, where the priority is to change the experience of one's product, as a form of stimulation or to reduce boredom. The search for various possibilities occurs when people are in a good mood, or when there is little stimulation elsewhere in their environment. In the case of food and beverages, the search for variation can occur because a phenomenon is known as sensory-specific satisfaction. The familiarity of a brand affects the trust in a brand, which in 
turn affects the intention to buy. However, consumers' tendency to change brand choices over time means that marketers will never be able to relax with the belief that once they have won customers.

Based on various studies it can be concluded that variables such as nutritional information, packaging graphics and country of origin are highly positively correlated with consumer purchasing behavior and marketers must focus on these packaging elements. On the other hand, packaging size, packaging design, packaging material, packaging color, and product information have a weaker positive correlation with consumer purchasing behavior and therefore marketers must precisely focus on these aspects so that positive correlations can be improved with consumer buying behavior.

Daily consumers are faced with purchasing decisions. Not all purchasing decisions are treated in the same way. Because some decisions are more complex than others and therefore require more effort by consumers. But other decisions are routine and require little effort (Schiffman, Kanuk, and Hansen, 2008). The term decision entails the selection of an option from at least two alternative brand choices. Regardless of the varying decision-making situations and the levels of consumer decision-making, the following factors influence the purchase decisions of consumers. These factors include external (culture, subculture, groups, situation, social class, and family; internal (perception, attitude, knowledge, personality, lifestyle, involvement, and roles) and marketing factors (product, package aesthetics, promotion, distribution, service and price) [9]

The reading of the message in the package continues to be made when eating food chips. Inadvertently directed eyes repeatedly see packaging illustrations. Color identity and packaging image become signs. How to socialize and visual promotions on social media by using familiar terms or calls in cyberspace; also affects the success of a product. At least if it is done, as part of how to market crispy food products, this is a sign that the promotion of these products meets the rules of visual media literacy.

\subsection{Externalization}

Another factor that influences is the consumer's perspective on a product. Different perspectives produce different views or views on a product. Husserl analyses the essence of the elements of pure consciousness in a detailed way. The way to find these essences includes at first two methodical steps: (1) the transcendental-phenomenological reduction and (2) the eidetic reduction. And there is a third step, which is described in other works of Husserl and which leads to a more definite eidos: (3) the eidetic variation [eidetische Variation].[10]

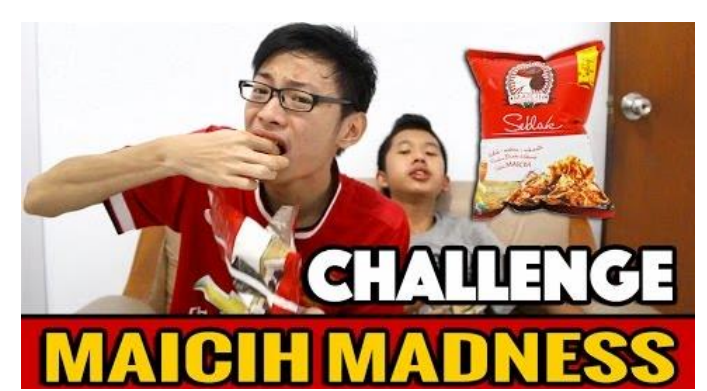

Fig 3. Discouraging the level of courage on Social Media (Source: https://bit.ly/2RfD5DA) 
Social media becomes social literacy learning which shows in what direction the trends of illustration style and social construction of the community exist. This means that social media has a strong influence to inspire consumers to understand the meaning of packaging. Given that an "official" market has been formed, this is experienced as objective reality. This is "there," outside the individual regardless of acknowledgment or the opposite argument. "consumers cannot expect the desire to buy away." Someone externalizes this "official" market and cannot understand it through introspection; he must go out and actively learn whatever he desires to know.

Referring to the data there are five patterns of knowledge construction - radiation, circulation, simulation, socialization, and contextualization, emphasizing various aspects of learning in the construction process of knowledge externalization, objectification, and internalization [11]. These different aspects of learning reveal that consumer learning is a collective effort that is socially embedded in community development, in the practical work of learners, and in everyday community life. Consumers are in the empirical social world to share their knowledge, to generate new knowledge, and to transfer their knowledge stocks into sub-social structures such as local communities. The process of visual media literacy externalization can be materialized, one of which is by endorsing public figures that are easily associated with the product in question. For example, Keripik Gagap products with public figures, Azis Gagap.

\section{Conclussion}

The results of the study show that packaging that is more desirable to consumers is: 1 ). The concept of eastern cultural philosophy, objectified by the graphic ornaments of regional icons. 2). Consumer interpretation is built when repeated packaging illustrations are set or seen when consumers consume these foods; 3 ). There is a social context narrative that is discourse and deliberately disseminated through social media. These three findings are the basis for packaging design that is creative and has selling value. Strengthening the deepening of visual media literacy on the internet makes the solution at every stage of the packaging design process to truly understand the packaging trend.

\section{Acknowledgements}

The author would like to express such gratitude to the Trisakti University Community Service Agency for the wonderful cooperation and contribution with the assisted village officials. Also not forget to mention, the Center for the Study of the Faculty of Art and Design in the design plan for publication media

\section{References}

[1] J. R. Pohtam, P. K. Deka, and C. Dutta, Impact of Packaging on Consumer Buying Behaviour, vol. 1, no. 1. 2016.

[2] M. N. Khuong and T. M. Hong, "The Impact of Product Packaging Design on Consumer Repurchase Intention - A Study of VinaMilk, Vietnam," Int. J. Innov. Manag. Technol., vol. 7, no. 5, pp. 219-223, 2016. 
[3] R. Kauppinen, "Post-operative pain management methods and nursing role in the relief of pain of total knee replacement patients Gunna Pana Sandika Gedara," no. December, 2015.

[4] P. L. Berger and D. A. N. Thomas, "Teori Konstruksi Sosial dari Peter L. Berger dan Thomas Luckman," UNS Semarang, pp. 1-13, 2018.

[5] K. Dan, P. Islam, and K. Kuncirpembelajaran, "TEOR1 PEMBELAJARAN DALAM PANDANGAN KONSTRUKTIVISME DAN PENDIDIKAN ISLAM Sukiman 1 Abstrak," vol. 3, no. 1, 2008.

[6] A. K. Agariya, A. Johari, H. K. Sharma, U. N. S. Chandraul, and D. Singh, "The Role of Packaging in Brand Communication,” Int. J. Sci. Eng. Res., vol. 3, no. 2, pp. 1-13, 2012.

[7] M. Genet, C. von Deuster, C. T. Stoeck, and S. Kozerke, "3D myofiber reconstruction from in vivo cardiac DTI data through extraction of low rank modes," Proc. 23rd ISMRM, p. 343, 2015.

[8] R. Setiowati and Y. Liem, "SOCIAL SCIENCES \& HUMANITIES Impact of Packaging Design on Perceived Quality, Perceived Value , Brand Preference, and Repurchase Intention of Candy Products in Jakarta," vol. 26, no. August, pp. 297-306, 2018.

[9] Munyaradzi Mutsikiwa and J. Marumbwa, "The Impact of Aesthetics Package Design Elements on Consumer Purchase Decisions: A Case of Locally Produced Dairy Products," $J$. Bus. Manag., vol. 8, no. 5, pp. 64-71, 2013.

[10] “May 2005 (C) Copyright by Wolfgang Brauner 1," no. May, pp. 1-10, 2005.

[11] A. Sica, H. Knoblauch, R. Wilke, P. L. Berger, and T. Luckmann, "Review Reviewed Work ( s ): The Social Construction of Reality: A Treatise in the Sociology of Knowledge . by Peter L . Berger and Thomas Luckmann Review by: George Simpson Source: American Sociological Review, Vol . 32 , No . 1 ( Feb ., 1967 ), pp ., "Hum. Stud., vol. 39, no. 1, pp. 51-69, 2016. 